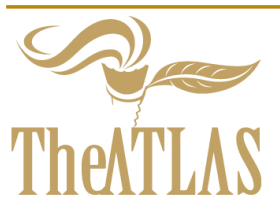

\title{
Transdisciplinarity and Environmental Education: Comprehensions about Silence and Being in Vedanta
}

\author{
Samuel Lopes Pinheiro ${ }^{1}$ and Humberto Calloni ${ }^{2},{ }^{1}$ Doctorate student at Environment Education Program \\ at Federal University of Rio Grande, Brazil, member of GEC (Complexity research group); ${ }^{2}$ Phd in Education and Full \\ Professor at Federal University of Rio Grande, Brazil, leader of GEC (Complexity research group) E-mail: \\ samuelshankara@gmail.com;E-mail: hcalloni@mikrus.com.br
}

Received 3 December, 2018; Revised February 20, 2019 Accepted February 21, 2019

Copyright (C)2019 Samuel Lopes Pinheiro and Humberto Calloni. This is an open access article distributed under the Creative Commons Attribution License (https://creativecommons.org/licenses/by/4.0/), which permits unrestricted use, distribution, and reproduction in any medium, provided the original work is properly cited.

Available online February 24, 2019 at www.atlas-journal.org, doi: 10.22545/2019/0116

\section{T} his present work aims to briefly present a transdisciplinary thesis done in a Post-Graduation Program in Environmental Education in Brazil in the level of Master's degree. The focus was the concept of "Silence" and "Being" in Vedanta (an Indian philosophy) perspective to elaborate about the foundations of Environmental Education. The study begins by reflecting on Western ways of being and the evidence of a Western paradigm that signals innumerable crises. Further, concepts of Vedanta are presented and then the reflection passes through a hermeneutic of silence, assuming practices of silence and meditation as a search for a sense of being that strengthens aspects such as Learning to Be and Learning to Live. From the interaction of knowledge between East and West, it is announced an Integral Environmental Education as necessary in the socio-environmental thinking and action, which corresponds in a non-dualistic way of integrating aspects of life.

Keywords: Transdisciplinarity; environmental education; silence; being; vedanta.

\section{Introduction}

This text is a small part of a broader study, a transdisciplinary thesis done in Master's degree in Environmental Education. The entire text of the thesis has 179 pages distributed in 3 chapters: i) Reflections East-West West-East; ii) A hermeneutic of silence; iii) For an integral Environmental Education. The main objective of that study was to understand a path of interaction of knowledge between West and East through the comprehension of Being and Silence of Vedanta Philosophy. From this movement, interrelate with the debate of the field of Environmental Education and its foundations with the questioning 
about human and nature.

Here it follows some chosen parts of each chapter in order to provoke the feeling of the whole work. This study is a try of encounter between Eastern and Westerns philosophies to make a transdisciplinary movement of the knowledge in the sense to create space to an integral perspective for Environmental Education. The concepts of Silence and Being according to Vedanta philosophy together with an understanding about the crises that goes with the Western paradigm, then a hermeneutic of Silence passing through the understanding of the silence of meditation and in the end some topics to be worked out in terms of Environmental Education.

Methodologically this encounter between East and West occurs through complex thinking and a transdisciplinary approach. However, to sketch an image of this methodological process, we creatively place two deities in rapprochement, one deity of the ancient Greeks, the Hermes, and the other, the Shiva, of the Indians. The French philosopher and mathematician Michel Serres (1930 -) uses the image of the god Hermes of Greek mythology as an allegory to explain this movement of knowledge construction. Because of the various attributes of this Greek deity, such as being a messenger and related to hermeneutics. Hence the hermeneutic name itself, comes from the name hermes.

If, in Western terms, the metaphor of the god Hermes is used to signal hermeneutics and approximations of distant linear times; in Eastern terms, the metaphor of the god Shiva appears to represent the movement and the dance of transformation. It is par excellence the divinity of the yogins and is often represented as a yogin, with compressed and tangled hair. The myth creates a contiguous sense to the established meaning, revealing the creative force responsible for the unconscious change of history. One should not ask what myths mean, because myths do not mean, they operate. When, from a distance, we perceive meanings, the myths have already distanced themselves and their place has been occupied by codes that sometimes organize our way of living and speaking [2].

The myth then appears as a sense operator. The hyper-rationalization of the Western technical world has left us orphans of the imaginary aspects of being. Myth, being replaced by reason, leaves a void in the creative dimensions of the human. Then we can take up the myth, not in its archaic sense, but now renewed by reason itself, knowing how to articulate it as an operator of meaning.

Shiva is the god belonging to the Hindu trinity, composed of Brahma-Vishnu-Shiva. Shiva is the third, the number three in this relationship. While Brahma is the creation, the number one; Vishnu is the maintenance aspect, the number two; Shiva is the aspect of destruction-transformation, the number three. In addition to the character of the myth, of the forms these deities represent and are represented, some Eastern conceptions, such as the Vedanta Philosophy, regard the Hindu trinity as a philosophical explanation for the phenomenal material world itself. The world and all the beings experiment this mentioned trinity. In general, here in this work, Hermes in a metaphorical way helps us to think about the hermeneutics of silence, its different attributions and conceptions throughout historical linear time, and Shiva, helps us to make and image the transdisciplinary and transformational movement in the field of Environmental Education fundamentals.

\section{Reflections about Utopia and Transdisciplinarity in the Context of Environmental Education}

In this scenario of life crisis that we observe in the contemporaneity, Environmental Education stands out as a concrete utopia under construction. That is because Environmental Education is situated at a nodal point of articulation about what to do as humanity, whether in the individual or collective sphere, and due to it is connected to the dimension of the environment. This characteristic can be thought as a regenerative aspect of Environmental Education, considered utopian. The term "utopia" in our "hypermodern times", as posed by the French thinker Gilles Lipovetsky (1944-) is fragile [3]. Other authors also point out the lack of values, or the growing of uncertainty of historical movements, such as the Polish Zygmunt Bauman (1925 - 2017) and the Portuguese Boaventura de Souza Santos (1940 -). Utopia is also discredited as a scientific value or path that must be imbricated, because the collective utopias of the twentieth century ended up collapsing in ethical terms when its effectiveness in practice.

From this characteristic of Environmental Education, we could think with Bauman that posits that today we do not have utopias nor dystopias 
guiding collective ends to the good society: "Everything, so to speak, runs on behalf of the individual". Zygmunt Bauman points out that, in contemporary times, utopias (a better world) should be thought through critical reflection on existing practices and beliefs to make explicit that "one thing is missing" [5]. But what is really missing? Or is it always necessary to have a certain sense of existential emptiness to propel us towards new horizons?

Here we have a possible reflection or elucidation about this feeling that something is missing, precisely in the lack of sense of Being. For there is a crisis of meaning, where individuals live without a transforming utopian horizon, nor of themselves, much less of the human and ecosystemic relationships. So, it is necessary to revisit the category of utopia, while still present in our socio-environmental actions. With it, utopia, to push what Boaventura de Souza Santos, already in the 1980s, called the "emergent paradigm". Because, according to this author, the dominant paradigm shows signs of collapse and we are at a threshold moment where we perceive signs of the new. At this point, one realizes the need to construct a science that accounts for the complex relations of the humanities with each other and with the environment. SOUZA SANTOS (2000) speaks not of a utopia properly, but of a "heterotopia" [6]. Instead of the invention of a place situated somewhere or elsewhere, the author proposes "a radical displacement within the same place: ours" [7]. But how can we characterize this common place, called "ours", if we are more and more individualized and under artificial protections?

For Gilles Lipovetsky there was the consecration of the present in the relationship of man with time and the death of collective utopias. But, at the same time, there is the "intensification of pragmatic attitudes and scientific forecasting and prevention" [8]. This opens up an expansion of the sense of present time because there is a constancy of thought in the future. As the temporal relation of the present is extended, people complain of a lack of time. Instead of the collective sacrifices that were made in the past in the name of a common political cause, we now sacrifice the individualized time of the present with the fear of the future even more uncertain.

While utopia remains on the horizon as a motivational factor for the human being, it seems that it works in the sense of giving fuel to the walker. But when utopia becomes achievable, we tend (as hu- manity) to a dystopia, or to the antithesis of utopia. At least, these are the impressions left by the collective experiences of the recent past. Nevertheless, from this sense of discrediting utopia, I believe that the utopian senses of the human being are to be recovered because While utopia remains on the horizon as a motivational factor of the human being, it seems that it works in the sense of giving fuel to the walker. But when utopia becomes achievable, we tend (as humanity) to a dystopia, or to the antithesis of utopia. Or, at least, these are the impressions left by the collective experiences of the recent past. Nevertheless, from this sense of discrediting utopia, I believe that the utopian senses of the human being are to be recovered because we are devoid of horizons and dreams in an empty sense of the present, preferentially inflamed by the astute consumerism of globalized society, which is inserted in human dreams through many ways.

Thus, Environmental Education is understood here as a conducive field to pedagogies that chase the drives of life, in the encounter with the other and in the regeneration of the senses of being. It recognizes the current civilizational crisis and throws itself in the adventure of building new senses of being against the hopelessness and fatalism of an abyss as the inevitable destiny of humanity. At the same time, it does not self-deceive itself with a naive optimism that will save everything in the end, but which seeks to understand the present and the material reality, opening up to the different dimensions of the human spirit, recognizing its limitations and uncertainties. This work takes part of a perspective that understands that the dialogue of knowledge, cultures and worldviews are pertinent for the maintenance of the diversity of life and for the knowledge of the Other and of Oneself. In this process, tries to contribute to the revitalization of the relation nature-humanity and for a planetary ethic.

In this sense, transdisciplinarity guides us that knowledge is a construction that is done among people, within the framework of a society that is not closed [9]. It is also done in nature, the original environment of the world, where the horizons and the borders of action are given. It is understood, therefore, the knowledge as being in interminable construction. Thus, knowledge only makes sense and can only be understood in its updating. This is done through the joints, in the intersections of interest and in the overcoming of the epistemological frontiers 
that have been broadly delineated in the last 300 years of the history of science. Transdisciplinarity, as the trans prefix indicates, concerns what is at the same time between disciplines, across different disciplines and beyond any discipline. Its objective is the understanding of the present world, for which one of the imperatives is the unity of knowledge [10].

In this way it is possible to update knowledge through the dialogue of knowledges. To go beyond the epistemological frontiers of conventional disciplinary knowledge, putting the Eastern and Western knowledge into dialogue. For this is one of the great separations still lingering in knowledge, which may reflect innumerable other separations embedded in human thought and action itself.

For the Indian philosopher Jiddu Krishnamurti (1895 - 1986), the crisis we often address is an "internal crisis" and we are not willing to resolve this [11]. In Western education there is no interest in engaging in the perception of oneself as it can be found in the interest Eastern knowledge. The author argues that modern education is transforming us into entities without understanding and our actual education does very little to help us discover our individual vocation [12].

In turn, one of the incongruities of education may lie in the established relationship between doing and suffering [13]. This is because this doing (the inward look, or the action of self-reflexive silence) is impregnated with suffering, which makes it difficult to meet pleasure and learning, and learning with pleasure, by using Basarab Nicolescu terminologies. The process of observing oneself internally does not correspond to a common practice of the contemporary Westerners, neither in educational practices, nor in daily life, nor in environmental perception. Hence the importance of the discussion about silence because it signals to this need of internally observation. The interaction between the inner being and the external being would thus correspond to improvements in levels of perception and levels of reality [14]. From the multiple contacts between levels of perception, new possibilities arise between levels of reality, realizing transdisciplinarity in action.

The dual conception is real at a certain level of reality ${ }^{1}[15]$. Sometimes the predominance of dual

\footnotetext{
1 "The different levels of reality are accessible to human knowledge thanks to the existence of different levels of perception, which are in a one-to-one correspondence with the levels of Reality. These levels of perception allow
}

vision seems to be accentuated, taking on the airs of separatism and fragmentation, as one claims to be the only prism of interpretation of reality. Life in its multidimensionality, coupled with this dual mode, closed to these fragmentary conditionings of human existence, is co-opted by the power games of relationships and becomes a hostage of its own condition, closing in a single level of reality, that is, the polarization of dualism. The fragmented vision becomes mediocre, because it shatters and shrinks in the face of the importance we give to the material in front of the spiritual, subject to the object (or the opposite) and human in front of nature. Stimulated by the predominant fragmentary view, we trigger a tendency toward relationships of hierarchical superiorities, when we feed, feedback, and reproduce the established dual conception.

The transdisciplinary vision is resolutely open insofar as it goes beyond the field of the exact sciences and demands their dialogue and their reconciliation with the humanities and the social sciences as well as with art, literature, poetry and spiritual experience. $^{2}$

In this sense, transdisciplinarity does not appear to be a superficial search for a planetary homogenization that closes and makes sectarizations. On the contrary, it presumes rigor, encourages openness and tolerance as critical steps for maintaining alertness so as not to fall into the traps of fragmentation or absolute scientism, which may be unable to recognize itself in the Other and in other knowledge.

\section{Getting to Know the Concept of Being and Silence in Vedanta}

It is normally considered the following classification among the Indian philosophical schools: Nyaya, Vaisesika, Sankhya, Yoga, Mimamsa e UttaraMimansa (or Vedanta). These are orthodox representatives, that is, they accept the authority and relevance of Vedas reading. Among the orthodoxes that rebound Vedas and, in a certain way, also have a connection with these writings, we find: Carvaka, Jainism and

an increasingly general, unifying, encompassing view of Reality without ever completely exhausting it" [16].

${ }^{2}$ Article 5 of the Charter of Transdisciplinarity, available in The manifesto of Transdisciplinarity [17]. 
Buddhism. The fundamental main texts to the study of Vedanta tradition are: Upanisad, Bhagavad Gita and Brahma-sutra. The second of them, Bhagavad Gita is part of Vedas and is a further text, inserted inside the Indian epic text called Mahabharata. The last one is called Nyaya-prasthana, because it shows the lessons of Vedanta through a logical order [18].

In The Tao of Physics, the Austrian physicist Fritjof Capra affirms that Vedanta is a philosophical tradition of intellectual accurate work that embodies a variety of Indian mystical lines [19]. It is based on Upanishads ${ }^{3}$ and subsequent literary productions which continue the argumentation under the same terms of a concept of Brahman ${ }^{4}$, that is "not personal and free from any mythological content" [20].

A meaning of non-dualism appears in Vedanta, and it happens due to a recurring understanding that everything is connected to everything in the world of phenomena. This Brahman, generically translated as "The Absolute", actually, on the understanding of Vedanta, does not have a close totality in itself, because it is infinite and not describable through close qualifiers, although it undertakes several qualities in its expression. It is not a whole, in a hypostatizing sense that would solve everything, but only an understanding of the interactional network established by all the beings and their consciousness since one of the Vedanta lessons is that the consciousness is Brahman. This meaning of non-duality had already been in Upanishads and Shankara reaffirms this assertive with their books and comments in the VIII A.D. Shankara strongly influenced people of its time, in which its philosophy was not claimed in India, but also abroad, as one of the most valuable works by the mankinds geniuses, even though Shankara stood not as the creator of a thinking, but as a successor of what already was present in Upanishads.

The nature of Being in Vedanta is Satchidananda. Sat means knowledge, Chid, existence, and Ananda, bliss. These characteristics are the ones of Being, that is either the Whole or the Absolute. It is also the nature of Being and the integral parts of the Whole. Both parts and Whole are identical twins of a life experimentation common process. As Brahman is identical to the self in Vedanta Philosophy, the real nature of each individual self is defined as truth,

\footnotetext{
${ }^{3}$ Ancient texts that frequently stem from comments of Vedas. They date all the way back to periods before Buddha, probably between the sixteenth and seventh centuries B.C.

${ }^{4}$ Sanskrit word that is translated sometimes as "The Whole", "The Absolute", or "The Universal Principle".
}

knowledge and infinite [21]. As the nature of the Being is limitless existence, knowledge and bliss, it means the individual being is also like that. Thus, the being has in itself the possibility to emerge in a continuous becoming to be.

Afterwards, about the tensions between the being and non-being, a fragmented view or not, it is highlighted the importance of the oriental philosophies discussion, as the Vedanta Philosophy that is here presented, it may collaborate, since it advertises, as a matter of complexity, about the meaning of uniduality, to which Edgar Morin refers [22]. This is due to the fact that the Vedanta Philosophy argues about the fragmentations, how to deal with opposite polarities observed in the world of life, at the same time it warns of the perception of a present unit concurrent with dualities.

One of the ways to deal with dualities, according to the oriental conceptions, is the silence, or the silence that fosters meditativeness since it arises, in several oriental lines of thought, as a window to the inner vision. The silence is, for these traditions, opposite to what we normally associate with this Word, active. Silence in an active way, deliberately done as a conscious self-awareness exercise, is a work of inner feeling expansions that provoke the reflection about itself as a "self" that objectifies a notion of "self" to rethink itself.

In this approach, the meditative silence is a work of looking at itself, in a sense of self-production of itself, not anymore as one more narcissistic mechanism of competition with itself and others or effectiveness for the sake of effectiveness. Indeed, it is done in order to see the completeness of the being and have the other as an extension. The simple fact of seeking selfawareness operates an ongoing displacement of itself which makes the subject not only consider itself, but also the other. This way, they turn themselves into subjects who search for a wide horizon of perception adjusted in a new environment of relationships. The feelings of ethics and autoethics emerge at the core of the subject as a fundamental direction to arise itself in the world [23].

In the transdisciplinary thinking, silence of the being seems to stand out as an intermediation between levels of reality in Manifesto of Transdisciplinarity [24]. Silence as an interaction membrane between the outer human being and the inner one as well as subjectivity and objectivity. In search for contact between levels, silence allows the listening of one and 
the other side, between the parts and the levels of perceptions.

The environmental education, supposed to be dialogical, brings humbleness to the others world pronunciation listening. It also offers self-awareness because it produces recognition of my other "selves", my own ignorance, which is no longer to alienate [25]. The lack of dialogicity is not opposite to silence, but it complexifies the meaning of environmental educability. Consequently, it inserts the third included secretly, because it touches and let it be touched by subjects and objects in the relationship. Transdisciplinarity and silence coexist pretty well since they act, as emphasized by Nicolescu, "in the name of a vision of balance between human being innerness and outterness" [26].

\section{Foundations for an Integral Environmental Education}

To integrate in Environmental Education may mean the search for antagonistic and complementary pole comprehension that the complex thinking has been signalizing in its methods. Furthermore, it is essential to know how to articulate the sapiens and demens aspects of the humane, East and West, material and spiritual, culture and nature as Edgar Morin mentions we are nature and culture simultaneously [27]. In the context of the fundamentals in Environmental Education, some possibilities guide us to the sense of integrativeness. Concepts such as subjectivity, time and temporality of formations, selfawareness are brought and, still, the aspect of spirituality, in a nondogmatic way, but as a transspiritual meaning. This transspiritual perspective crosses religions, not closing them but opening to what they have in common. Therefore, the concept of silence or meditative silence transits through all these other concepts previously mentioned.

The dual nature of the subject, along with the complex idea of selfishness, can suggest about the human relationship and nature in Environmental Education. Moreover, it may refer to how much the human being has focused on itself in a logic induced by the capitalist system. In this system, life is compressed by orienting competitions of behaviors in diverse sectors either due to status and money or vanities and other forms of competition. Thereby, individuals are led to wreck both fraternity signs and ecophilia in its etymological sense, which is related to the fraternal love by the environment. In times of barbarism development, it is quite revolutionary to bet on solidarity.

Effectiveness produces racing for production, leading to competitive societies, in which creativity, affectivity, spirituality and search for human being completeness do not have any place. In this regard, we may reflect about it, with the support of Environmental Education theorists, whose notes suggest that the school is a privileged place for that, since it is soaked with creativity [28]. In addition, it is possible to reach the goal of Environmental Education as integral, aside from encouraging the insertion of values such as creativity and imagination on the human being formation as a whole, playful dimension aspects of human beings.

From that, we could infer that self-awareness and meditative silence (Vedic visions arguing in favor) are stimuli to regenerate utopian feelings on the ways of life, justifying the concern with utopia initially listed in this text. Due to this, eastern visions as Vedanta appeal to an identification with the collectiveness, betting in trust and solidarity with others. Thus the encounter East and West, stimulates the regeneration of solidary senses in human relations and interspecies.

The author Edgar Morin also uses the word "selfawareness" in the analysis of the computo and the ongoing spiral of $\operatorname{cogito}^{5}[29]$. He distinguishes the term self-awareness in his approach by affirming it does not mean knowledge of him/herself. For Morin, it means the indiscriminate cognitive dimension in the self-organization and inherent to the computo is knowledge of the being about oneself. According to the philosopher, "self-observation learning is part of the learning of clarity" [30].

Therefore, we understand that self-awareness transits through the path of subjectivity and temporalities to compute reflectively about oneself in a construction-destruction-maintenance circle of ideas/concepts/virtualities that one has of itself. Self-awareness does not cancel subjectivity. Instead, it takes place due to this, returning to itself. In this

\footnotetext{
${ }^{5}$ The cogito begins to appear as a spiral ring. In a first degree it produces the objective "me", which is trivial. In a second degree, it produces the self-identity of the egoself, which is insufficient. In the third degree, it produces the "I am" of the "self-self". We must also see that this circuit operates the passage from the objective "me" to the subject "I" and vice versa, basing them on each other [33].
} 
process, inner environment communicates with the outer one, as well as in the reverse way in a spiral movement.

\section{Final Considerations}

"It is absolutely essential to explore the infinite capacity of fascination of human consciousness in order to make the reenchantment of the world possible."

BasarabNicolescu [31]

In the transdisciplinary perspective, knowledge is understood as a construction and search for self-awareness [32]. Thus, not being about predetermined reason or already established, the possibility of a discussion on the role of education through creative exploration and knowledge construction is prior. This way, meditative silence of eastern inspirations as manifestation of human spirit may be a guide of movements towards self-awareness which retroact in the inner and outer being simultaneously, stimulating a transdisciplinary education.

The search for other epistemologies and ontologies may be significant in the field of Environmental Education, which is concerned with the diversity and socializing scientifically popular, ancient and spiritual knowledge of different peoples, ethnicities and areas of the planet. The transdisciplinary approach in Environmental Education may mean the strengthening and respect for diversities while it allows the meeting of knowledge and pushes the creation of the new.

For the field of Environmental Education, we understand that the most contribution of this study is the recovery of a meaning of non-duality as ethical foundation to think the relationship human-nature, inspired by Vedanta, whose idea of unity in diversity has been claimed for centuries. Politically, it may reverberate in different ways, as the claiming for creative times, and times for self-awareness and inner growing. These should be in the same basis of the human formation while we are stimulated to learn how to live, be and coexist, expressions that are frequently observed in texts about complex thinking. The discussion of a meaning of non-duality regenerates the search for fundamentals in Environmental Education, which is ruled by its own search for meaning of being and questions about which relationships we are creating among human beings and between human beings and non-human beings.
On the same way of learning to live and learning to be, Edgar Morin discusses Educations need to teach how to transform the knowledge into wisdom so that we can deal with our own mental, cognitive and psychic mechanisms in an integral way [34]. This exercise of search for integrativeness of the being may be favored by the self-awareness meditative silence in Education and also in Environmental Education. That is because human formations are not a heap of watertight knowledge that is centralized either in the subjects or in the objects. Rather, it is a dynamic process that places and (re) organizes those parts that are recognized in a complex network of individual and collective work.

The transgression of dichotomies, as matter/spirit, subject/object and human/nature, also needs to be understood in different contexts, such as the school. We may stimulate an integral comprehension of human condition, regenerating the meaning of being through supportive ethics and integration. This ethical meaning must be followed in our theoretical discussions of the environmental fields. Besides that, we have to notice how these discussions may create movements in society, culture and human formation as a whole, as well as the meeting with eastern philosophies may represent new inspirations along.

Beyond the world of opposites, we have to realize the unity, not putting variations of specific nature aside. The inner and outer world are phenomenal aspects of reality that finds unity in that - the subject -, the one who experience itself as a communicable bridge between inner and outer realities. The path to self-awareness is not abandoning one side and exclusively living the other one but finding a proper calculation which allows us to articulate its relationship. Moreover, the transdisciplinary vision is a search for transgression of duality, opposite to different binary peers, as subject and object, matter and consciousness, reductionism and holism, diversity and unity. As Nicolescu indicates, knowledge is neither inner nor outer, but it is simultaneous and needs to stimulate a non-resistance to this observation of an isomorphism relationship [35].

The re-enchantment of "the world of life" emerges as a way of resistance to the project which consolidates with the great western culture (based on separateness, dishonesty and fear). When we search for other sources of wisdom and examples of relationships with the environment, as we find in native people and eastern wisdom, we reinforce the hope 
of a counter hegemonic praxis that is in same origin of the Environmental Education and its history.

Author Contributions: Paper was written collaboratively by two authors.

Funding: This research received no external funding.

Conflicts of Interest: The authors declare no conflict of interest.

\section{References}

[1] Serres, M., (1996). Diálogo sobre a ciência, a cultura e o tempo: conversas com Bruno Latour. Lisboa: Instituo Piaget.

[2] Galimberti, U., (2003). Rastros do sagrado. São Paulo: Paulus.

[3] Lipovetsky, G., (2004). Os tempos hipermodernos. São Paulo: Editora Barcarolla.

[4] Bauman, Z., (2001). Modernidade lquida. Rio de Janeiro: Zahar.

[5] Bauman, Z., (2001). Modernidade lquida. Rio de Janeiro: Zahar.

[6] Souza Santos, B.d., (2000). A crítica da razão indolente: contra o desperdício da experiência. São Paulo: Cortez.

[7] Souza Santos, B.d., (2000). A crítica da razão indolente: contra o desperdício da experiência. São Paulo: Cortez.

[8] Lipovetsky, G., (2004). Os tempos hipermodernos. São Paulo: Editora Barcarolla.

[9] Abreu Junior, L., (1996). Conhecimento Transdisciplinar: o cenário espistemolgico da complexidade. Piracicaba: Editora Unimep.

[10] Nicolescu, B., (1999). O manifesto da transdisciplinaridade. São Paulo: Triom.

[11] Krishnamurti, J., (1973). Educaão e significado da vida. São Paulo: Cultrix.

[12] Krishnamurti, J., (1973). Educaão e significado da vida. São Paulo: Cultrix.

[13] Nicolescu, B., (1999). O manifesto da transdisciplinaridade. São Paulo: Triom.

[14] Nicolescu, B., (1999). O manifesto da transdisciplinaridade. São Paulo: Triom.

[15] Nicolescu, B., (1999). O manifesto da transdisciplinaridade. São Paulo: Triom.

[16] Nicolescu, B., (1999). O manifesto da transdisciplinaridade. São Paulo: Triom.

[17] Nicolescu, B., (1999). O manifesto da transdisciplinaridade. São Paulo: Triom.
[18] Mahadevan, T.M.P, (1998). Invitación a la filosofa de la india. México-D.F.: Fondo de cultura económica.

[19] Capra, F., (2011). O Tao da Fúsica: Um paralelo entre a Física Moderna e o Misticismo Oriental. São Paulo: Editora Pensamento-Cultrix.

[20] Capra, F., (2011). O Tao da Fsica: Um paralelo entre a Fsica Moderna e o Misticismo Oriental. São Paulo: Editora Pensamento-Cultrix.

[21] http://www.teses.usp.br/teses/disponiveis/8/8139/ tde-05122007-155442/pt-br.php (accessed November 11, 2018).

[22] Morin, E., (2012). O mtodo 5: a humanidade da humanidade. Porto Alegre: Sulina.

[23] Morin, E., (2012). O mtodo 5: a humanidade da humanidade. Porto Alegre: Sulina.

[24] Nicolescu, B., (1999). O manifesto da transdisciplinaridade. São Paulo: Triom.

[25] Sorrentino, M.; et al, (2010). Em busca da sustentabilidade educadora ambientalista. Revista ambientalMENTEsustentable. vol. I, núm. 9-10, 7-35.

[26] Nicolescu, B., (1999). O manifesto da transdisciplinaridade. São Paulo: Triom.

[27] Morin, E., (2005). O método 2: a vida da vida. Porto Alegre: Sulina.

[28] Reigota, M., (2004). O que é Educaão Ambiental. São Paulo: Brasiliense.

[29] Morin, E., (2005). O método 2: a vida da vida. Porto Alegre: Sulina.

[30] Morin, E., (1999). Reformar o Pensamento: a cabeça bem feita. Lisboa/Portugal: Éditions du Seuil Instituto Piaget.

[31] Nicolescu, B., (1999). O manifesto da transdisciplinaridade. São Paulo: Triom.

[32] Abreu Junior, L., (1996). Conhecimento Transdisciplinar: o cenário espistemológico da complexidade. Piracicaba: Editora Unimep.

[33] Morin, E., (2005). O método 2: a vida da vida. Porto Alegre: Sulina.

[34] Morin, E., (1999). Reformar o Pensamento: a cabeça bem feita. Lisboa/Portugal: Éditions du Seuil Instituto Piaget.

[35] Nicolescu, B., (1999). O manifesto da transdisciplinaridade. São Paulo: Triom. 


\section{About the Authors}

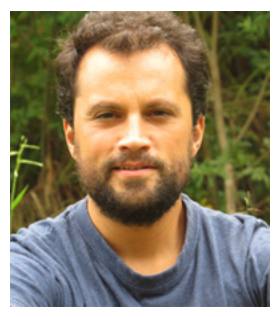

Samuel Pinheiro currently, is a Ph.D. student in Environmental Education at Federal University of Rio Grande (FURG/Brazil) and during his master's degree also in Environmental Education he worked with the concept of Silence and Being in Vedanta Philosophy. He comes from a multiple formation in different areas such as Management, Languages, Philosophy and also in Yoga. This makes his interesting in education closer to transdisciplinarity and complex thinking. His Ph.D. research is concerned with subjectivity and convergent pedagogies. He is a member of Grupo de Estudo e Pesquisa da Complexidade (GEC).

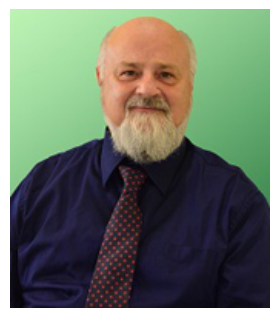

Dr. Humberto Calloni has a degree in Philosophy from the Federal University of Rio Grande do Sul (1985), a degree in Pedagogy from the Federal University of Rio Grande do Sul (1987), a Master's degree in Education from the Federal University of Rio Grande do Sul (1990) and a Ph.D.in Education from Federal University of RGS (2002). He is currently a Professor at the Federal University of Rio Grande (FURG), a reviewer of the Environment and Education periodical, a reviewer of the Journal of Education (UFPel), a reviewer of the periodical of Momento (Rio Grande). He has experience in Education, with emphasis on Fundamentals of Education. Acting mainly on the following topics: Interdisciplinarity, dialogue, formation, and humanism. He is the leader of the Research Group of Complexity Study (GEC). 